\title{
The Higher Performance Expectation, the Less Territorial Behavior? A Psychological Mechanism Moderated by Performance Comparison
}

\author{
Na Li \\ School of Management, Shanghai University, Shanghai, China \\ Email: angelia0217@outlook.com
}

How to cite this paper: Li, N. (2021). The Higher Performance Expectation, the Less Territorial Behavior? A Psychological Mechanism Moderated by Performance Comparison. Open Journal of Social Sciences, 9, 140-157.

https://doi.org/10.4236/jss.2021.91010

Received: December 10, 2020

Accepted: January 15, 2021

Published: January 18, 2021

Copyright ( 2021 by author(s) and Scientific Research Publishing Inc. This work is licensed under the Creative Commons Attribution International License (CC BY 4.0).

http://creativecommons.org/licenses/by/4.0/

\begin{abstract}
The purpose of this study is to investigate the role of psychological safety in the relationship between high performance expectation and territorial behavior. Territorial behaviors refer to the actions people expressed to mark and defend certain objects that they believe belong to them. Drawing on leadermember exchange theory, we proposed that high performance expectation negatively affects employees' territorial behavior through the mechanism of psychological safety and that this indirect effect is moderated by performance comparison. We tested our hypotheses using data from 229 employees in Shanghai, China. We found that high performance expectation had a negative indirect effect on employees' territorial behavior through psychological safety and performance comparison moderated the indirect relationship. The moderated mediation relationship was stronger among followers who had lower rather than higher performance compared to average.
\end{abstract}

\section{Keywords}

High Performance Expectation, Psychological Safety, Performance Comparison, Territorial Behavior

\section{Introduction}

Territoriality is innate and universal. Within organizations, it is common for people to claim and defend their control of a variety of physical and social objects (Brown, Lawrence, \& Robinson, 2005). Moreover, individuals may form different territories. They may have a strong attachment to certain objects (i.e., workplaces, roles or, relationships) and see it as something that only they can use (Brown \& Menkhoff, 2007). The exclusive ownership will hinder knowledge 
sharing, reduce interpersonal communication, and injure reputation (Brown et al., 2005). In contrast, they can still be intensely attached and feel strong ownership over, however, the ownership is not exclusive (Brown \& Menkhoff, 2007). From example, if employees view the entire organization as a territory, they may consider the ideas, spaces, and relationships as shared or belonging to the organization, rather than the individual. Previous studies have suggested that one way to reduce individual territorial behavior is to encourage people to view the territories as sharing by the whole organization. Therefore, managers need to take measures to improve employees' psychological safety and organizational identity, thus encouraging employees to put more effort to help, improve and defend the organization (Brown \& Menkhoff, 2007) rather than occupying territories within the organization.

There exists an abundance of studies exploring the way to encourage employees to invest efforts in the organizations, for example, job rewards, social atmosphere, organizational support, etc. (De Vos, Buyens, \& Schalk, 2003; Hui, Lee, \& Wang, 2015; Lee, Liu, Rousseau, Hui, \& Chen, 2011). However, high performance expectation, a leadership behavior with great magic powers, has been ignored. High performance expectation has been defined as a leadership behavior that the leader's expectation for excellence, quality, or high performance on the part of followers (Podsakoff, MacKenzie, Moorman, \& Fetter, 1990). To explicate whether and how a leader's high performance expectation affects employees' territorial behavior in the workplace, we adopt leader-member exchange theory. In light to leader-member exchange theory, the leader's high performance expectation to the part of followers facilitate the formation of the high LMX relationship and give them greater support and encouragement, which in turn affect employees' belief of reciprocity and improve their investment in the organization.

Moreover, the study examines the psychological mechanism through which high performance expectation influences employees' territorial behavior. Employees who perceived high performance expectation are likely to form mutual respect that goes beyond trust, leading to high psychological safety (Walumbwa \& Schaubroeck, 2009). Psychological safety refers to the individuals' perception that they are comfortable being themselves (Edmondson, 1999) and able to show and employ themselves without fear of negative consequences to self-image, status, or career (Kahn, 1990). As an important psychological intervening mechanism linking leader behavior and outcomes (Men et al., 2018), psychological safety is considered to be closely related to employees' willingness to communicate with others and "open" their territories (Brown, Crossley, \& Robinson, 2014). Thus, we argue that high performance expectation implications for the psychological safety of employees, which, in turn, associates with employees' territorial behavior.

However, for employees with different levels of performance, the incentive effect of high performance expectation may be different. People always evaluate their opinions and abilities by comparing with others (Festinger, 1954). In organizations, employees evaluate their relative abilities and status by comparing 
with the average team performance-performance comparison. According to behavioral plasticity theory, there are differences in the degree to which individuals react to the external environment, and the external cues affect their attitudes and perceptions differently (Pierce, Gardner, Dunham, \& Cummings, 1993). Individuals with high ability rely more on their skill to perform their jobs, but less confident, low ability individuals rely more on their work environments, and they are more susceptible to the external environment, for better or worse (Brockner, 1988; Detert \& Burris, 2007). Therefore, employees with lower performance comparison may respond more to high performance expectation than those with higher performance comparison. Then, we tested a moderated mediation model proposing an indirect relationship between high performance expectation and territorial behavior that is mediated by psychological safety and moderated by performance comparison.

In this study, we mainly investigate whether high performance expectation can predict territorial behavior through psychological safety. Moreover, we argue that performance comparison may operate as a significant moderator in the relationship between high performance expectation and psychological safety. Figure 1 presents this research model.

This study seeks to make three unique contributions. First, we examine the effect of high performance expectation on territorial behavior in the workplace. According to LMX theory and psychological safety literatures, we develop a mediation model that links high performance expectation to territorial behavior through psychological safety. Second, we extend high performance expectation literature from humanism perspective, we propose that high performance expectation is not only a way to improve employees' performance, but also contributes to employees' psychological safety. Finally, in considering employees' performance comparison as a moderator, we contrast the different types of employees based on their perceived performance compared to average. This will allow managers to concern underperformers for the purpose of enhancing their psychological safety effectively. Moreover, we identify the performance comparison as a condition that moderates the indirect relationship between high performance expectation and territorial behavior through psychological safety.

\section{Theoretical Background}

\section{Territorial behaviors}

Brown et al. (2005) defined territoriality as an individual's behavioral expression

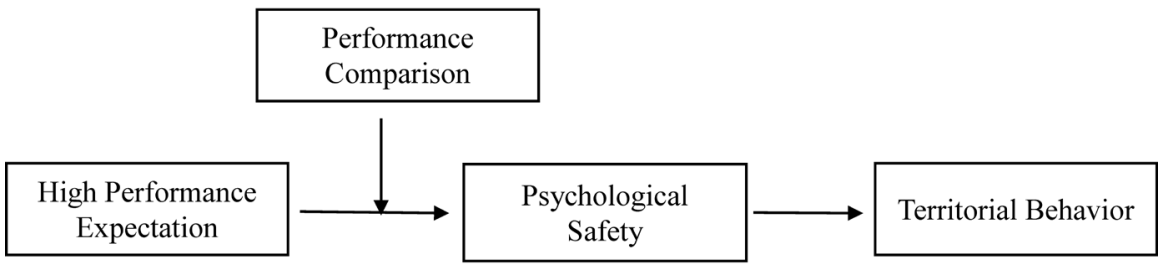

Figure 1. Research model. 
of his or her feelings of ownership to a physical or social object. Territorial behaviors are used to construct, communicate, maintain, and restore territories around those objects in the organization toward which one feels proprietary attachment (Brown et al., 2005). The behaviors divided into two main categories: marking and defending. Marking refers to the behaviors of organizational members that construct and communicate to others that one has psychological ownership over particular organizational objects. It can be further divided into two types: identity-oriented marking and control-oriented marking (Brown et al., 2014). Identity-oriented marking serves to express one's identity to others in the organizations. Control-oriented marking is used to communicate to others that an organizational object has been claimed. By marking this announcement, others in the organization know that certain territories have been claimed (Brown \& Zhu, 2016). However, this claim does not necessarily prevent others from possessing or using the territories, and others may also try to get control of the territory because of its value (Brown et al., 2014). So individuals could engage in defending behavior to prevent or respond to others' infringements. Defending can also be divided into two types: anticipatory defending and reactionary defending. Anticipatory defending serves to maintain a territory by thwarting others' infringement actions while reactionary defending is used to undermine the infringement and restore the territory after an infringement (Brown et al., 2005).

Based on the division of territorial behaviors mentioned above, Brown (2009) developed a territoriality scale which promoted the development of empirical research on territorial behavior. However, the scale has limitations, such as only applicable to the physical workplace. Thus, Brown et al. (2014) adapted Brown (2009)'s measure of claiming and anticipatory defending behavior to apply to a variety of types of territories. Specifically, Brown et al. (2014) divided the measurement of territorial behavior into two dimensions-claiming behavior and anticipatory defending behavior to apply to a variety of objects (i.e., workplace, role, relationship, idea, knowledge and tool).

Territorial behavior and psychological safety

Psychological safety has been defined as individuals' perceptions of the consequences of taking interpersonal risks in their work environment. It describes a feeling that individuals are comfortable being themselves (Edmondson, 1999) and feel able to show and employ oneself without fear of negative consequences to self-image, status, or career (Kahn, 1990). Notably, Psychological safety can be studied at three different levels (i.e., individual, team, organization) based on the research results (Edmondson \& Lei, 2014). Following Kark and Carmeli (2009)'s argument that individual perceptions of the work environment are likely to result in individual behavioral outcomes (i.e., territorial behavior), we conducted this study on individual-level psychological safety.

Territorial behavior is the consequence of defensive orientation (Wang, Law, Zhang, Li, \& Liang, 2019). By definition, it is a self-other boundary regulation mechanism that involves marking or communicating an object that is owned by 
a person or group and defending territorial infringement (Altman, 1975). This perception highlights that the establishment of physical and social boundaries through territorial behavior can help people protect valuable objects and prevent unwanted intrusions (Brown, 2009). In particular, when individuals face unsafe factors or psychological threats (Kahn, 1990) which involves an undesired environment that diminishes predictability and threatens one's sense of control (Tangirala \& Alge, 2006; Tu, Lu, Choi, \& Guo, 2018), they will reinforce self-protection to ensure their status and career in organization (Ford, 1996; Rogers, 1957). Therefore, one of the effective ways to reduce workplace territorial behavior is to enhance employees' psychological safety.

Psychological safety is meant to suggest a sense of confidence that stems from mutual respect and trust among team members (Edmondson, 1999). It describes individuals' perception of the reduction of uncertainty and ambiguity in social interactions (Gong, Cheung, Wang, \& Huang, 2012). The previous study has argued that psychological safety helps people overcome defensiveness against uncertainly in real life (Schein, 1985). When employees perceived psychological safety, they may assume that others are unlikely to infringe on their possessions, and thus, territorial behavior is unnecessary. Rely on mutual respect and trust, team members gain the benefits of cooperate and freely share resources with their coworkers, with little risk of losing ownership (Brown et al., 2014). Moreover, Edmondson, Kramer, and Cook (2004) argued that psychological safety encourages employees to contribute their ideas and actions to collective work. Therefore, if the employees perceived safety, controllable environment and favorable interpersonal relationships in the organization, they are more likely to break territorial boundaries, reduce defensiveness and contribute the resources to the organization. In contrast, when employees perceived psychological unsafety, they may anticipate that sharing the resource may not result in personal gains but risk loss of control over their possessions, and thus, they may maintain control the resources and mitigate the risk (Brown et al., 2014). This argument is consistent with the findings of Brown et al. (2014) that a high trust environment (with trust defined similarly to psychological safety, as the one will not be harmed by another) (Detert \& Burris, 2007) reduces the territorial behavior associated with psychological ownership. Specifically, we predict:

Hypothesis 1: Psychological safety is negatively related to territorial behavior.

High performance expectation and psychological safety

Psychological safety reflects the belief that engaging in risky behaviors (like sharing resources to others) will not lead to personal harm (Detert \& Burris, 2007). Put simply, employees who fear territories ownership losses are likely to choose territorial behavior. Researches have suggested that leader behavior contributes to feelings of psychological safety (Edmondson, 1999). Edmondson et al. (2004) argued that when leaders showed openness, availability, and accessibility, employees are likely to feel psychological safety at work. However, high performance expectation, a leader behavior with great potential power, has been ig- 
nored. High performance expectation reflects the leader's expectation for excellence, quality or high performance on the part of followers (Podsakoff et al., 1990). Research on the Pygmalion effect had found that individuals who face high performance expectation show greater effort and performance than others (Sutton \& Woodman, 1989). This is in part because high performance expectations lead superiors to interact with performers differently (Dai, Dietvorst, Tuckfield, Milkman, \& Schweitzer, 2017). When a leader has more positive performance expectations for a particular subordinate, she or he will like that subordinate more (Whiteley, Sy, \& Johnson, 2012).

The affect/effort theory proposed by Rosenthal (1989) for the mediation of interpersonal expectancy effects argued that the way leaders treat high expectancy employees in line with the principles of LMX theory (Bezuijen, van den Berg, van Dam, \& Thierry, 2009). Based on the LMX theory, the leader develops different quality relationships with subordinates by the division of in-group and out-group members. The in-group members received greater support, guidance, and encouragement from leaders. They were usually given more challenging assignments and more opportunities for personal growth and learning (Boies \& Howell, 2006; Liden \& Graen, 1980). Specifically, the leader's high performance expectation to the part of followers facilitates the formation of the high LMX relationship, high mutual trust, and high interaction, which improve subordinates' psychological perception. In turn, the followers trust their leader has sufficient ability, benevolence, and integrity, thus they will be more comfortable about engaging in interpersonal risk taking under the leader's support and affirmation (Edmondson et al., 2004; Walumbwa \& Schaubroeck, 2009). Moreover, the leader's high performance expectation promotes the high self-expectation of employees, that is, the beliefs about their abilities to complete the given tasks effectively (Eden, 1990). Compared to in-group members, the out-group members receive little support and guidance and formed low LMX relationships, thus, they lack resources and confidences to perform. The uncertain environment reduces their psychological safety. We therefore predict:

Hypothesis 2: High performance expectation is positively related to psychological safety.

Taking $\mathrm{H} 1$ and $\mathrm{H} 2$ together, we posit that psychological safety is a crucial bridge linking high performance expectation to territorial behavior. According to LMX theory, high performance expectations promote high levels of reciprocal trust and respect, and improve employees' psychological safety perceptions, thus, employees respond to the better treatment with the investment of resources and energy (Gerstner \& Day, 1997) rather than occupying the territories within the organization. Therefore, employees who perceived high performance expectation engaged in less territorial behavior because they are psychologically safety. Then, we predict:

Hypothesis 3: high performance expectation has a negative indirect effect on territorial behavior through psychological safety. 
The Moderate Effects of Performance Comparison

Although high performance expectation has a significant impact on improving employees' psychological perception, the influence degree is likely to vary as a function of performance comparison. Performance comparison is a pervasive psychological phenomenon in human social life and embedded deeply in organization life (Greenberg, Ashton-James, \& Ashkanasy, 2007). Notably, individuals inevitably compare with others in their work team to form self-evaluation. Performance comparison in this study reflects a subjective evaluation by comparing performance with average team performance. As similar with average across LMX, the choice of average team performance as the comparison referent is concerned with individuals' relative standing in the team because comparing with only one or small porting of the team members is unlikely to provide such information ( $\mathrm{Hu} \&$ Liden, 2013). In addition, some social comparison theorists have also found that people tend to choose "average" or the whole team as the referent point and evaluate whether they are better or worse than average (Blanton, Buunk, Gibbons, \& Kuyper, 1999; Moore, 2007). When perceived performance is higher than average team performance, individuals could get positive self-evaluation, higher organizational status and feel more confident about their ability (Blanton et al., 1999; Detert \& Burris, 2007).

Schein and Bennis (1965) described psychological safety as "the perception of one can take chances" which indicated two main sources of psychological safety-feelings of their environment and the ability to cope with the change (Aranzamendez, James, \& Toms, 2014). For the individuals with high performance comparison, they have enough confidence to tackle with the uncertainty and overcome the insecurity factors. Conversely, individuals with low performance comparison than average may lack personal confidence or job security. According to behavioral plasticity theory, there are differences in the degree to which individuals react to the external environment (Pierce et al., 1993), individuals with high ability are more adaptable and rely more on their skills to perform their jobs, while those with low ability rely more on their work environments (Schuler, 1977). Therefore, employees with low performance comparison have a stronger response to the high performance expectation of leaders. This argument is consistent with prior research suggesting that employees with low self-esteem might respond more to positive expectation leadership and gain a larger increase in performance than those with higher self-esteem. In keeping with the argument that the Pygmalion effect was larger when involving underachievers or those with lower self-efficacy (McNatt, 2000), the path from high performance expectation to psychological safety is stronger for low performance comparison. Accordingly, we hypothesize:

Hypothesis 4: Performance comparison moderates the relationship between high performance expectation and psychological safety. Such that the positive relationship between high performance expectation and psychological safety will be stronger among followers with low performance comparison. 


\section{Moderated mediation relationship}

Taken as a whole, performance comparison moderates the relationship between high performance expectation and psychological safety, it is also likely that performance comparison will conditionally influence the strength of the indirect relation between high performance expectation and territorial behavior, thereby demonstrating a pattern of moderated mediation between the variables in our study. Because we predict a weak (strong) relation between high performance expectation and psychological safety in a high (low) performance comparison, we hypothesize the following:

Hypothesis 5: Performance comparison moderates the relationship between high performance expectation and territorial behavior via psychological safety. Such that the mediating effect of psychological safety will be stronger among followers with low performance comparison.

\section{Method}

\section{Sample and Procedure}

The sample used in this study consists of 350 employees from three enterprises in Shanghai. A cover letter attached to each questionnaire explained the objectives and procedures of the survey, which ensured anonymity and confidentiality. The questionnaires consisted of self-reported high performance expectation of leaders, psychological safety, performance comparison, and territorial behavior. The scales were originally constructed in English. To assure equivalence of the measures in the Chinese and the English versions of the survey instrument, we performed a standard translation and back-translation procedure (Brislin, 1980).

We collected 297 questionnaires, of which 229 are valid with an effective rate of $65.42 \%$. Of the respondents, $65.9 \%$ were female, $76.7 \%$ had a bachelor's degree or above, the mean age was 30 years old, the average monthly pretax income was 6991 yuan, and the average working time with their superiors is 22.97 months.

\section{Measures}

The participants responded to each of the following items using a 5-point $\mathrm{Li}$ kert-type scale ranging from 1 (strongly disagree) to 5 (strongly agree) unless otherwise noted.

Territorial behavior. Territorial behavior was measured using a six-item scale instrument developed by Brown et al. (2014). A sample item was "I hide some 'work' details or tricks to keep others from understanding it." The scale's reliability was 0.832 .

High performance expectation. We measured high performance expectation using a three-item scale instrument by Podsakoff et al. (1990). A sample item was "The superior have high performance requirements for me." The scale's reliability was 0.825 .

Psychological safety. Psychological safety was measured by a seven-item scale 
by Edmondson (1999). A sample item was "This department can accept members to take risks." The scale's reliability was 0.758 .

Performance comparison. We adapted Williams and Anderson (1991)'s fouritem scale of performance to measure employees perceived performance compared with average team performance. A sample item was "I can finish my work better compared to the team average." The scale's reliability was 0.916 .

Control Variables. Previous studies have shown that certain socio-demographic variables like gender can affect territorial behavior (Mercer \& Benjamin, 1980). Thus, we speculated that territorial behavior is also likely to be influenced by other relevant demographic characteristics. In the current research, employees were asked to report the gender $(1=$ male, $2=$ female $)$, age, education ( 1 = primary school, 2 = junior middle school, 3 = high school or technical secondary school, 4 = junior college, 5 = bachelor's degree, $6=$ master's degree, 7 $=\mathrm{PhD})$, monthly income before tax, working experience with current supervisor.

\section{Analysis method}

We use Mplus 7.4 for confirmatory factor analysis (CFA) to test the validity of variable measurement. Then, SPSS 20.0 software was used to conduct descriptive statistics and correlation analysis on the variables involved in this study. Finally, we used SPSS 20.0 and Mplus 7.4 to test the hypothesis.

\section{Results}

\section{Preliminary analyses}

We conducted a series of confirmatory factor analyses using Mplus 7.4 to examine the construct validity of our measures. As shown in Table 1, results showed that the hypothesized four-factor model provided a better fit to the data than any other models, indicating support for the distinctiveness of the constructs in the study.

Since the data of the study were collected through self-report measures, common method bias could inflate the perceived relationships. We then performed the common latent factor approach to examine the common method bias (Podsakoff, MacKenzie, Lee, \& Podsakoff, 2003). Specifically, the method uses a

Table 1. Results of confirmatory factor analysis of the measurement models.

\begin{tabular}{ccccccc}
\hline Measurement models & $\chi^{2}$ & DF & RMSEA & CFI & TLI & SRMR \\
\hline Five-factor model: four factor and CLF & 135.031 & 59 & 0.075 & 0.948 & 0.931 & 0.076 \\
Four-factor & 117.505 & 59 & 0.066 & 0.960 & 0.947 & 0.065 \\
Three-factor (combined PS and TB into one factor) & 304.064 & 62 & 0.131 & 0.834 & 0.792 & 0.100 \\
$\begin{array}{c}\text { Two-factor (combined PS and TB into one factor, and } \\
\text { combined HPE and PC into one factor) }\end{array}$ & 533.787 & 64 & 0.179 & 0.678 & 0.608 & 0.136 \\
$\begin{array}{c}\text { One factor (combined all items into one factor) } \\
\text { ( }\end{array}$ & 729.270 & 65 & 0.211 & 0.545 & 0.454 & 0.163 \\
\hline
\end{tabular}

Note. $\mathrm{N}=229$. $\mathrm{PS}=$ psychological safety; $\mathrm{TB}=$ territorial behavior; $\mathrm{HPE}=$ high performance expectation; $\mathrm{PC}=$ performance comparison. CLF means a common latent factor. 
common latent factor (CLF) to capture the common variance among all observed variables in the model. The results showed that adding a common method factor did not increase the model fit significantly. The variation ranges of RMSEA, CFI, TLI, and SRMR are all below 0.02 (Table 1). Thus, common method bias was not found to be a serious problem in the present study.

We next conducted analyses to decide whether it was necessary to control all demographic characteristics. By eliminating control variables uncorrelated with the dependent variables, we avoided potential spurious effects that controls may have when they are significantly related to the predictor, but not the criterion variables (Kraimer, Seibert, Wayne, Liden, \& Bravo, 2011). In separate regression equations in which territorial behavior was regressed on these five potential control variables, monthly income before tax, gender, and Working experience with current supervisor significantly predicted territorial behavior. We thus controlled for them.

\section{Descriptive Statistics}

The means, standard deviations, Cronbach's alpha, and correlations of the variables were presented in Table 2. As the results suggested, high performance expectation was positively related to psychological safety; psychological safety was negatively correlated with territorial behavior.

\section{Tests of Hypotheses}

Hypotheses 1 posits that psychological safety is negatively related to territorial behavior, and Hypotheses 2 proposes a positive relationship between high performance expectation and psychological safety. As shown in Table 3, Model 2 indicates that psychological safety is negatively associated with territorial behavior $(\beta=-0.281, p<0.010)$, thereby confirming Hypotheses 1 . The Model 3 supports Hypotheses 2 , that is, high performance expectation is positively related to psychological safety $(\beta=0.24, p<0.001)$.

Table 2. Descriptive statistics and correlations among variables.

\begin{tabular}{|c|c|c|c|c|c|c|c|c|c|c|c|}
\hline Variables & M & SD & 1 & 2 & 3 & 4 & 5 & 6 & 7 & 8 & 9 \\
\hline 1. Education & 4.834 & 0.700 & - & & & & & & & & \\
\hline 2. Monthly income before tax & 6.991 & 3.100 & $0.311^{\star * *}$ & - & & & & & & & \\
\hline 3. Gender & 1.659 & 0.475 & 0.001 & $-0.136^{\star}$ & - & & & & & & \\
\hline 4. Age & 29.983 & 4.947 & -0.084 & $0.311^{\star * *}$ & -0.016 & - & & & & & \\
\hline $\begin{array}{l}\text { 5. Working experience with } \\
\text { current supervisor }\end{array}$ & 22.965 & 21.213 & -0.036 & $0.213^{* *}$ & -0.023 & $0.207^{\star \star}$ & - & & & & \\
\hline 6. High performance expectation & 3.613 & 0.811 & $0.193^{* *}$ & $0.175^{* *}$ & 0.024 & 0.007 & 0.023 & $(0.825)$ & & & \\
\hline 7. Psychological safety & 3.853 & 0.551 & $0.180^{* *}$ & 0.073 & $0.181^{\star *}$ & $-0.170^{\star *}$ & -0.055 & $0.364^{* * *}$ & $(0.758)$ & & \\
\hline 8. Performance comparison & 3.978 & 0.648 & $0.142^{*}$ & $0.138^{*}$ & 0.054 & 0.064 & -0.016 & $0.352^{* * *}$ & $0.302^{* * *}$ & $(0.916)$ & \\
\hline 9. Territorial behavior & 2.366 & 0.763 & 0.051 & $0.248^{\star * *}$ & $-0.191^{\star *}$ & 0.110 & $0.174^{\star *}$ & 0.062 & $0.181^{\star *}$ & 0.126 & $(0.832)$ \\
\hline
\end{tabular}

Notes. $\mathrm{N}=229$. Internal consistency estimates (alphas) are on the diagonal; ${ }^{\star} p<0.050,{ }^{* *} p<0.010$. 
Table 3. Results of hierarchical regression analysis.

\begin{tabular}{|c|c|c|c|c|c|}
\hline \multirow{2}{*}{ Variables } & \multicolumn{2}{|c|}{ Territorial behavior } & \multicolumn{3}{|c|}{ Psychological safety } \\
\hline & M1 & M2 & M3 & M4 & M5 \\
\hline Monthly income before tax & $0.047^{\star *}$ & $0.05^{\star *}$ & 0.009 & 0.006 & 0.005 \\
\hline Gender & $-0.261^{*}$ & $-0.203^{\star}$ & $0.206^{* *}$ & $0.194^{* *}$ & $0.192^{* *}$ \\
\hline $\begin{array}{l}\text { Working experience with current } \\
\text { supervisor }\end{array}$ & $0.005^{*}$ & 0.004 & -0.002 & -0.002 & -0.001 \\
\hline High performance expectation & 0.028 & 0.095 & $0.24^{\star * \star}$ & $0.198^{\star * *}$ & $0.21^{\star * *}$ \\
\hline Psychological safety & & $-0.281^{\star *}$ & & & \\
\hline Performance comparison & & & & $0.158^{* *}$ & $0.131^{\star}$ \\
\hline $\mathrm{HPR} * \mathrm{PC}$ & & & & & $-0.123^{*}$ \\
\hline$R^{2}$ & 0.103 & 0.137 & 0.168 & 0.198 & 0.217 \\
\hline$\Delta R^{2}$ & 0.087 & $0.118^{* *}$ & $0.153^{\star \star *}$ & $0.180^{\star *}$ & $0.196^{*}$ \\
\hline$F$ & $6.436^{* * *}$ & $7.099^{* * *}$ & $11.312^{* * *}$ & $11.002^{* * *}$ & $10.277^{* * *}$ \\
\hline
\end{tabular}

Notes. $\mathrm{N}=229 .{ }^{*} p<0.050,{ }^{* *} p<0.010$.

Hypotheses 3 depicted the indirect effect of high performance expectation on territorial behavior through psychological safety. We used nonparametric bootstrap methods (Edwards \& Lambert, 2007) to compute the 95\% bias-corrected Confidence Interval (CI) of the indirect effect. The bootstrapping results show that the indirect effect of high performance expectation on territorial behavior via psychological safety $(\beta=-0.07,95 \%$ CI $[-0.127,-0.029])$ was negative and significant. Therefore, Hypotheses 3 was supported.

Hypotheses 4 predicts that performance comparison moderates the relationship between high performance expectation and psychological safety. The regression results of Model 5 indicates that the interaction between high performance expectation and performance comparison is a significant, negative predictor of psychological safety $(\beta=-0.123, p<0.05)$. We drew an interaction plot following the procedures recommended by Dawson (2014). As shown in Figure 2 , simple slope test results show that the effect of high performance expectation on psychological safety was more pronounced and positive with lower rather than higher performance comparison, thereby supporting Hypotheses 4 .

Hypotheses 5 posits that performance comparison moderates the indirect effect of high performance expectation on territorial behavior through psychological safety. Following the suggestions of (Preacher, Rucker, \& Hayes, 2007), we used the Mplus 7.4 to examine the conditional indirect effects. As presented in Table 4, the conditional indirect effect for high performance expectation was stronger when the performance comparison is low $(\beta=-0.072,95 \%$ CI $[-0.157$, $-0.021])$ rather than high $(\beta=-0.032,95 \%$ CI $[-0.082,-0.005])$. Moreover, the difference between the indirect relationships was significant, with bootstrapping $95 \%$ CI being $(0.002,0.120)$ excluding zero. Therefore, our results supported the moderated mediation model. 


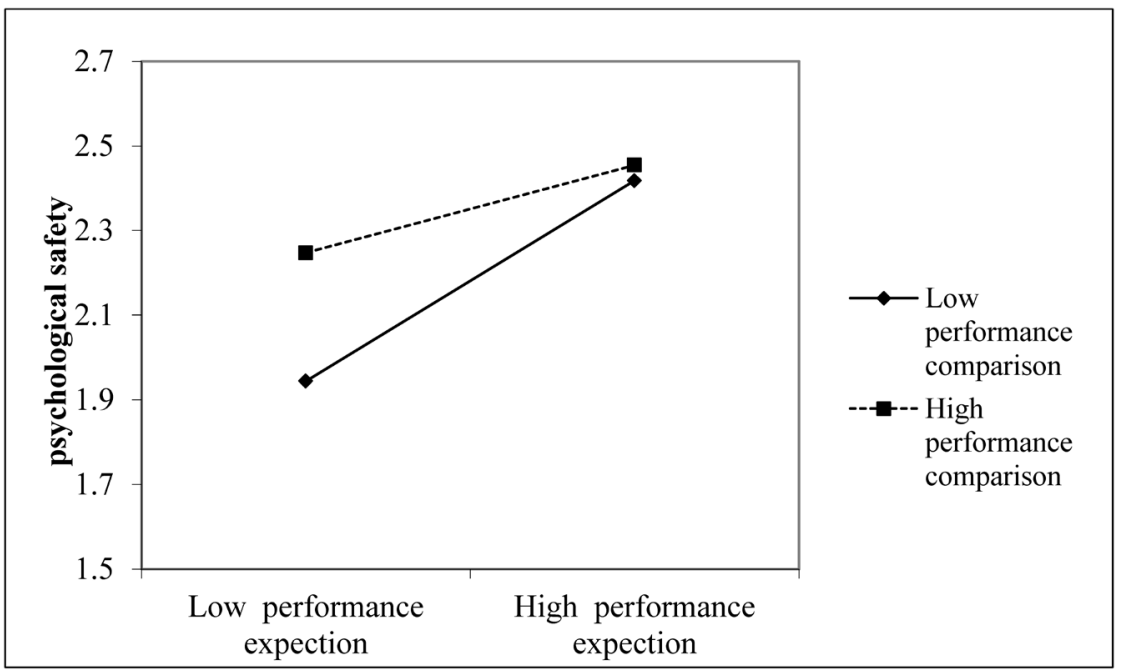

Figure 2. Interaction plot of high performance expectation and performance comparison predicting psychological safety.

Table 4. Indirect effects of high performance expectation on territorial behavior.

\begin{tabular}{cccc}
\hline \multirow{2}{*}{ Level of moderator } & \multicolumn{3}{c}{ Territorial behavior } \\
\cline { 2 - 4 } & $\boldsymbol{\beta}$ & SE & $95 \% \mathrm{CI}$ \\
\hline High (+1 SD) & -0.032 & 0.019 & $(-0.082,-0.005)$ \\
Low (-1 SD) & -0.072 & 0.034 & $(-0.157,-0.021)$ \\
DIFF & 0.041 & 0.029 & $(0.002,0.120)$ \\
\hline
\end{tabular}

Note. Bootstrap sample size $=5000$. CI, confidence interval.

\section{Summary of hypothesis test results}

The results of hypothesis test show that all the hypotheses mentioned in this paper are supported by data. This study found the relationship between high performance expectation and territorial behavior through psychological safety, and this relationship was moderated by the performance comparison.

\section{Conclusion}

The findings of this study showed the psychological safety was positively related to high performance expectation and negatively related to territorial behavior. We link high performance expectation to territorial behavior via psychological safety. Furthermore, we found the effect of high performance expectation on psychological safety was moderated by performance comparison. The positive relationship between high performance expectation and psychological safety was stronger among employees who had low rather than high performance compared to average. Finally, we examined the moderated mediation model that the effect size of high performance expectation on territorial behavior through psychological safety was moderated by the boundary condition of performance comparison.

1) Theoretical implications

Our study has several theoretical implications. First, our study extends the re- 
searches on antecedent variables of territorial behavior. Previous works regarding the exploration of antecedent variables of territorial behavior mostly centered on psychological ownership as a key psychological foundation (Brown et al., 2005, 2014). Nevertheless, leaders, as the organizational agent (Coyle-Shapiro \& Shore, 2007), has generally been left unexplored. Thom-Santelli (2009) suggested that workplace territorial expressions could be influenced by leader behaviors. Echoing the calls for exploring the leadership factors, this study demonstrated the indirect relationship between high performance expectation and territorial behavior. Moreover, we found psychological safety to be a crucial intervening variable in the high performance expectation-territorial behavior relation. Drawing on LMX theory and psychological safety literature, high performance expectation can enhance the development of employees' psychological safety, which in turn will reduce individual territorial behavior in the workplace.

Second, our results contribute to both the high performance expectation and psychological safety literature. Although studies of Pygmalion effect (Sutton \& Woodman, 1989) and goal-setting theory (Locke \& Latham, 1990) have confirmed that high performance expectation has an important impact on the improvement of work performance, little attention discussed the meaning of high performance expectation of the supervisor from humanism perspective. The present research demonstrated the positive relationship between high performance expectation and psychological safety.

Third, this study showed that the relationship between high performance expectation and psychological safety was conditional on the performance comparison. When the individuals' performance comparison is lower, high performance expectation has a greater influence on psychological safety. Previous studies of the process and mechanisms by which high performance expectation influences followers' performance have examined the underachievers or those with lower self-efficacy react stronger on Pygmalion effect (McNatt, 2000). In keeping this argument, our study adopted empirical method to verify the conclusion. Moreover, in focusing on moderating effect, our model helps explain both how high performance expectation influences individuals' territorial behavior, and for whom the high performance expectation can have the greatest effect. We found the indirect relationship between high performance expectation and territorial behavior through psychological safety to be contingent on individual differences in performance comparison.

2) Practical implications

Our study also provides some implications for managerial practices. One straightforward lesson from this study is that high performance expectation can enhance the development of employees' psychological safety, which in turn will reduce individual territorial behavior in the workplace. Therefore, high performance expectation is an effective incentive means to encourage employees to reduce individual territorial behavior and invest their resources and energy in the organization. Besides, organizations could take other measures to improve employees' 
psychological safety perception. For example, developing supportive, open, transformational and inclusive leadership styles (Edmondson, 1999) or managing subordinates' adventure and error (Kahn, 1990).

In addition, this study found that high performance expectation is an effective way to enhance employees' psychological safety. We concluded that high performance expectation is not only a way to improve employees' performance (Locke, 1990), but also contributes to the improvement of employees' psychological safety. Therefore, organization managers should recognize the possible power and influence of high performance expectation, support and communicate common beliefs to increase employees' motivation and effort and help them achieve that potential (McNatt, 2000).

Finally, our findings on the moderator role of performance comparison suggest that the impact of leader's high performance expectation to territorial behavior through psychological safety varies with different individuals. Therefore, leaders should "teach according to their aptitude", pay more attention to those who have low performance evaluation, and give them high performance expectation and encouragement. Such could make employees feel strong psychological safety, further heighten inhibitory effect on territorial behavior.

3) Limitations and future research

This study also has some potential limitations. First, our examples of high performance expectation, psychological safety, performance comparison, and territorial behavior came from the same source, which inevitably leads to a certain degree of common method variance. The purpose of this study was to explore the effect of employee perceived high performance expectation on territorial behavior, which seems to be more appropriate for self-reported measures of all constructs. Although we have taken steps to reduce and examine this issue, future research should examine our findings using multiple sources of data. Second, because our research was cross-sectional, we are unable to draw strong causal inferences regarding the variables' relationships. Although we had strong theoretical and logical reasons for causality, alternative causal models may be plausible. Therefore, longitudinal research designs are needed for future research. Third, the data were collected from three enterprises from Shanghai, which limited the generalizability of our results. Thus, future research should use samples from different regions, even different countries or conduct targeted survey for a single industry or region to enhance the external validity of the study, and further verify the conclusions.

\section{Conflicts of Interest}

The author declares no conflicts of interest regarding the publication of this paper.

\section{References}

Altman, I. (1975). Environment and Social Behavior: Privacy, Personal Space, Territory, and Crowding. New York, Monterey, CA: Brooks/Cole.

Aranzamendez, G., James, D., \& Toms, R. (2014). Finding Antecedents of Psychological 
Safety: A Step toward Quality Improvement. Nursing Forum, 50, 171-178. https://doi.org/10.1111/nuf.12084

Bezuijen, X. M., van den Berg, P. T., van Dam, K., \& Thierry, H. (2009). Pygmalion and Employee Learning: The Role of Leader Behaviors. Journal of Management, 35, 12481267. https://doi.org/10.1177/0149206308329966

Blanton, H., Buunk, B. P., Gibbons, F. X., \& Kuyper, H. (1999). When Better-than-Others Compare Upward: Choice of Comparison and Comparative Evaluation as Independent Predictors of Academic Performance. Journal of Personality and Social Psychology, 76, 420-430. https://doi.org/10.1037/0022-3514.76.3.420

Boies, K., \& Howell, J. M. (2006). Leader-Member Exchange in Teams: An Examination of the Interaction between Relationship Differentiation and Mean LMX in Explaining Team-Level Outcomes. The Leadership Quarterly, 17, 246-257.

https://doi.org/10.1016/j.leaqua.2006.02.004

Brislin, R. W. (1980). Translation and Content Analysis of Oral and Written Materials.

Brockner, J. (1988). Self-Esteem at Work: Research, Theory, and Practice. Lexington, MA: Lexington Books/D.C.

Brown, G. (2009). Claiming a Corner at Work: Measuring Employee Territoriality in Their Workspaces. Journal of Environmental Psychology, 29, 44-52. https://doi.org/10.1016/j.jenvp.2008.05.004

Brown, G., \& Menkhoff, T. (2007). Territoriality over Knowledge: Towards a Cross-Cultural Perspective. The Power of Knowing: Studies of Chinese Business in Asia, Special Issue of the Journal of Asian Business.

Brown, G., \& Zhu, H. (2016). "My Workspace, Not Yours”: The Impact of Psychological Ownership and Territoriality in Organizations. Journal of Environmental Psychology, 48, 54-64. https://doi.org/10.1016/j.jenvp.2016.08.001

Brown, G., Crossley, C., \& Robinson, S. L. (2014). Psychological Ownership, Territorial Behavior, and Being Perceived as a Team Contributor: The Critical Role of Trust in the Work Environment. Personnel Psychology, 67, 463-485.

https://doi.org/10.1111/peps.12048

Brown, G., Lawrence, T. B., \& Robinson, S. L. (2005). Territoriality in Organizations. Academy of Management Review, 30, 577-594.

https://doi.org/10.5465/amr.2005.17293710

Coyle-Shapiro, J. A. M., \& Shore, L. M. (2007). The Employee-Organization Relationship: Where Do We Go from Here? Human Resource Management Review, 17, 166-179. https://doi.org/10.1016/j.hrmr.2007.03.008

Dai, H., Dietvorst, B. J., Tuckfield, B., Milkman, K. L., \& Schweitzer, M. E. (2017). Quitting When the Going Gets Tough: A Downside of High Performance Expectations. Academy of Management Journal, 61, 1-54. https://doi.org/10.5465/amj.2014.1045

Dawson, J. F. (2014). Moderation in Management Research: What, Why, When, and How. Journal of Business and Psychology, 29, 1-19. https://doi.org/10.1007/s10869-013-9308-7

De Vos, A., Buyens, D., \& Schalk, R. (2003). Psychological Contract Development during Organizational Socialization: Adaptation to Reality and the Role of Reciprocity. Journal of Organizational Behavior, 24, 537-559. https://doi.org/10.1002/job.205

Detert, J. R., \& Burris, E. R. (2007). Leadership Behavior and Employee Voice: Is the Door Really Open? Academy of Management Journal, 50, 869-884.

https://doi.org/10.5465/amj.2007.26279183

Eden, D. (1990). Pygmalion in Management: Productivity as a Self-Fulfilling Prophecy. 
Lexington, MA: Lexington Books/D.C.

Edmondson, A. (1999). Psychological Safety and Learning Behavior in Work Teams. Administrative Science Quarterly, 44, 350. https://doi.org/10.2307/2666999

Edmondson, A. C., \& Lei, Z. (2014). Psychological Safety: The History, Renaissance, and Future of an Interpersonal Construct. Annual Review of Organizational Psychology and Organizational Behavior, 1, 23-43. https://doi.org/10.1146/annurev-orgpsych-031413-091305

Edmondson, A. C., Kramer, R. M., \& Cook, K. S. (2004). Psychological Safety, Trust and Learning in Organization: A Group-Level Lens.

Edwards, J. R., \& Lambert, L. S. (2007). Supplemental Material for Methods for Integrating Moderation and Mediation: A General Analytical Framework Using Moderated Path Analysis. Psychological Methods, 12, 1-12. https://doi.org/10.1037/1082-989X.12.1.1

Festinger, L. (1954). A Theory of Social Comparison Processes. Human Relations, 7, 117 140. https://doi.org/10.1177/001872675400700202

Ford, C. M. (1996). A Theory of Individual Creative Action in Multiple Social Domains. Academy of Management Review, 21, 1112-1142. https://doi.org/10.5465/amr.1996.9704071865

Gerstner, C. R., \& Day, D. V. (1997). Meta-Analytic Review of Leader-Member Exchange Theory: Correlates and Construct Issues. Journal of Applied Psychology, 82, 827-844. https://doi.org/10.1037/0021-9010.82.6.827

Gong, Y., Cheung, S.-Y., Wang, M., \& Huang, J.-C. (2012). Unfolding the Proactive Process for Creativity: Integration of the Employee Proactivity, Information Exchange, and Psychological Safety Perspectives. Journal of Management, 38, 1611-1633. https://doi.org/10.1177/0149206310380250

Greenberg, J., Ashton-James, C. E., \& Ashkanasy, N. M. (2007). Social Comparison Process in Organizations. Organizational Behavior and Human Decision Processes, 102, 22-41. https://doi.org/10.1016/j.obhdp.2006.09.006

Hu, J., \& Liden, R. C. (2013). Relative Leader-Member Exchange within Team Contexts: How and When Social Comparison Impacts Individual Effectiveness. Personnel Psychology, 66, 127-172. https://doi.org/10.1111/peps.12008

Hui, C., Lee, C., \& Wang, H. (2015). Organizational Inducements and Employee Citizenship Behavior: The Mediating Role of Perceived Insider Status and the Moderating Role of Collectivism. Human Resource Management, 54, 439-456.

https://doi.org/10.1002/hrm.21620

Kahn, W. A. (1990). Psychological Conditions of Personal Engagement and Disengagement at Work. Academy of Management Journal, 33, 692-724. https://doi.org/10.5465/256287

Kark, R., \& Carmeli, A. (2009). Alive and Creating: The Mediating Role of Vitality and Aliveness in the Relationship between Psychological Safety and Creative Work Involvement. Journal of Organizational Behavior, 30, 785-804.

https://doi.org/10.1002/job.571

Kraimer, M. L., Seibert, S. E., Wayne, S. J., Liden, R. C., \& Bravo, J. (2011). Antecedents and Outcomes of Organizational Support for Development: The Critical Role of Career Opportunities. Journal of Applied Psychology, 96, 485-500. https://doi.org/10.1037/a0021452

Lee, C., Liu, J., Rousseau, D. M., Hui, C., \& Chen, Z. X. (2011). Inducements, Contributions, and Fulfillment in New Employee Psychological Contracts. Human Resource 
Management, 50, 201-226. https://doi.org/10.1002/hrm.20415

Liden, R. C., \& Graen, G. (1980). Generalizability of the Vertical Dyad Linkage Model of Leadership. Academy of Management Journal, 23, 451-465.

https://doi.org/10.2307/255511

Locke, E. A. (1990). Work Motivation and Satisfaction: Light at the End of the Tunnel. Psychological Science, 1, 240-246. https://doi.org/10.1111/j.1467-9280.1990.tb00207.x

Locke, E. A., \& Latham, G. P. (1990). A Theory of Goal Setting and Task Performance. Upper Saddle River, NJ: Prentice-Hall, Inc.

McNatt, D. B. (2000). Ancient Pygmalion Joins Contemporary Management: A Meta-Analysis of the Result. Journal of Applied Psychology, 85, 314-322. https://doi.org/10.1037/0021-9010.85.2.314

Men, C., Fong, P. S. W., Huo, W., Zhong, J., Jia, R., \& Luo, J. (2018). Ethical Leadership and Knowledge Hiding: A Moderated Mediation Model of Psychological Safety and Mastery Climate. Journal of Business Ethics, 166, 461-472.

https://doi.org/10.1007/s10551-018-4027-7

Mercer, G. W., \& Benjamin, M. L. (1980). Spatial Behavior of University Undergraduates in Double-Occupancy Residence Rooms: An Inventory of Effects. Journal of Applied Social Psychology, 10, 32-44. https://doi.org/10.1111/j.1559-1816.1980.tb00691.x

Moore, D. A. (2007). Not So Above Average after All: When People Believe They Are Worse than Average and Its Implications for Theories of Bias in Social Comparison. Organizational Behavior and Human Decision Processes, 102, 42-58. https://doi.org/10.1016/j.obhdp.2006.09.005

Pierce, J. L., Gardner, D. G., Dunham, R. B., \& Cummings, L. L. (1993). Moderation by Organization-Based Self-Esteem of Role Condition-Employee Response Relationships. Academy of Management Journal, 36, 271-288. https://doi.org/10.5465/256523

Podsakoff, P. M., MacKenzie, S. B., Lee, J. Y., \& Podsakoff, N. P. (2003). Common Method Biases in Behavioral Research: A Critical Review of the Literature and Recommended Remedies. Journal of Applied Psychology, 88, 879-903.

https://doi.org/10.1037/0021-9010.88.5.879

Podsakoff, P. M., MacKenzie, S. B., Moorman, R. H., \& Fetter, R. (1990). Transformational Leader Behaviors and Their Effects on Followers' Trust in Leader, Satisfaction, and Organizational Citizenship Behaviors. The Leadership Quarterly, 1, 107-142. https://doi.org/10.1016/1048-9843(90)90009-7

Preacher, K. J., Rucker, D. D., \& Hayes, A. F. (2007). Addressing Moderated Mediation Hypotheses: Theory, Methods, and Prescriptions. Multivariate Behavioral Research, 42, 185-227. https://doi.org/10.1080/00273170701341316

Rogers, C. R. (1957). The Necessary and Sufficient Conditions of Therapeutic Personality Change. Journal of Consulting Psychology, 21, 95-103. https://doi.org/10.1037/h0045357

Rosenthal, R. (1989). Experimenter Expectancy, Covert Communication, and Meta-Analytic Methods. The 97th Annual Convention of the American Psychological Association, New Orleans.

Schein, E. H. (1985). Organizational Culture and Leadership. San Francisco, CA: Jossey-Bass Publishers.

Schein, E. H., \& Bennis, W. G. (1965). Personal and Organizational Change through Group Methods: The Laboratory Approach. New York: Wiley.

Schuler, R. S. (1977). Role Perceptions, Satisfaction and Performance Moderated by Organization Level and Participation in Decision Making. Academy of Management Jour- 
nal, 20, 159-165. https://doi.org/10.2307/255471

Sutton, C. D., \& Woodman, R. W. (1989). Pygmalion Goes to Work: The Effects of Supervisor Expectations in a Retail Setting. Journal of Applied Psychology, 74, 943-950. https://doi.org/10.1037/0021-9010.74.6.943

Tangirala, S., \& Alge, B. J. (2006). Reactions to Unfair Events in Computer-Mediated Groups: A Test of Uncertainty Management Theory. Organizational Behavior and Human Decision Processes, 100, 1-20. https://doi.org/10.1016/j.obhdp.2005.11.002

Thom-Santelli, J. (2009). Expressing Territoriality in Collaborative Activity. The GROUP 'O9 Proceedings of the ACM 2009 International Conference on Supporting Group Work, Sanibel Island, May 2009, 389-390. https://doi.org/10.1145/1531674.1531738

Tu, Y., Lu, X., Choi, J. N., \& Guo, W. (2018). Ethical Leadership and Team-Level Creativity: Mediation of Psychological Safety Climate and Moderation of Supervisor Support for Creativity. Journal of Business Ethics, 159, 551-565. https://doi.org/10.1007/s10551-018-3839-9

Walumbwa, F. O., \& Schaubroeck, J. (2009). Leader Personality Traits and Employee Voice Behavior: Mediating Roles of Ethical Leadership and Work Group Psychological Safety. Journal of Applied Psychology, 94, 1275-1286. https://doi.org/10.1037/a0015848

Wang, L., Law, K. S., Zhang, M. J., Li, Y. N., \& Liang, Y. (2019). It's Mine! Psychological Ownership of One's Job Explains Positive and Negative Workplace Outcomes of Job Engagement. Journal of Applied Psychology, 104, 229-246. https://doi.org/10.1037/apl0000337

Whiteley, P., Sy, T., \& Johnson, S. K. (2012). Leaders' Conceptions of Followers: Implications for Naturally Occurring Pygmalion Effects. The Leadership Quarterly, 23, 822-834. https://doi.org/10.1016/j.leaqua.2012.03.006

Williams, L. J., \& Anderson, S. E. (1991). Job Satisfaction and Organizational Commitment as Predictors of Organizational Citizenship and In-Role Behaviors Journal of Management, 17, 601-617. https://doi.org/10.1177/014920639101700305 